\title{
EFEITO DA RUPTURA CELULAR EM DIFERENTES MÉTODOS DE SECAGEM NO CONTEÚDO DE FICOCIANINA DA Arthrospira (Spirulina)
}

\author{
A. P. Q. LARROSA ${ }^{1}$, A. A. $\operatorname{COMITRE}^{1}$, L. B. VAZ ${ }^{1}$, L. A. A. PINTO ${ }^{1 *}$ \\ ${ }^{1}$ Universidade Federal do Rio Grande, Escola de Química e Alimentos \\ *e-mail: dqmpinto@furg.br
}

\begin{abstract}
RESUMO
A microalga Arthrospira (Spirulina), além do seu elevado teor de proteínas, apresenta uma rica fonte de pigmentos como a ficocianina, que possui ação antioxidante e anti-inflamatória, além de ser utilizada como corantes naturais em substituição aos sintéticos. Em vista da microalga ser termicamente instável, este trabalho tem como objetivo de analisar diferentes técnicas de secagem e métodos de ruptura para obter um maior rendimento de ficocianina. A Arthrospira Spirulina LEB-18 foi cedida pelo Laboratório de Engenharia Bioquímica-LEB da FURG, com concentração de $20 \%(\mathrm{~m} / \mathrm{m})$ de sólidos. As técnicas de secagem utilizadas foram o leito de jorro e a bandeja com escoamento paralelo do ar, e os métodos de ruptura foram moagem, micro-ondas e autoclave. As amostras de Arthrospira Spirulina foram analisadas quanto ao conteúdo de ficocianina, e seus extratos aquosos foram analisados no espectro de infravermelho (FTIR) para identificação dos grupamentos característicos da ficocianina. Os produtos desidratados foram avaliados quanto sua estrutura morfológica pela microscopia eletrônica de varredura (MEV). A secagem em leito de jorro combinada com o rompimento em micro-ondas apresentou melhores resultados em relação às amostras in natura e as secas sem ruptura. Os espectros de FTIR apresentaram os grupamentos característicos da ficocianina.
\end{abstract}

\section{INTRODUÇÃO}

As cianobactérias são organismos aquáticos e fotossintéticos conhecidos pelos seus ricos pigmentos e nutrientes, contendo elevado conteúdo proteico, sendo empregados em suplementos alimentares. Dentre as cianobactérias destaca-se a Arthrospira Spirulina, que possui atividade anticâncer e antimicrobiano via produção de compostos antioxidantes e pigmentos como ficocianina, ficocianobilina, aloficocianina dentre outros produtos (NUHU, 2013).
A ficocianina é um dos principais pigmentos da Arthrospira Spirulina que tem sido amplamente estudada devido à sua aplicação como corantes alimentícios e uso em cosméticos, em substituição aos corantes sintéticos (MARTELLI et al., 2014). A ficocianina é uma proteína pertencente à família das ficobiliproteínas caracterizada pela intensa coloração azul, e sua estrutura consiste de uma proteína e componentes nãoproteicos conhecido como as ficocianobilinas (FERNÁNDEZ-ROJAS, HERNÁNDEZJUÁREZ \& PEDRAZA-CHAVERRI, 2014). 
Diversos métodos têm sido investigados a fim de proporcionar melhores extrações e rendimentos no conteúdo de ficocianina (CHAIKLAHAN et al., 2011; MORAES, BURKERT \& KALIL, 2010), sendo que a operação de secagem é necessária para a obtenção da biomassa seca. A secagem da Arthrospira Spirulina, para posterior extração de ficocianina, tem sido empregada em diversas técnicas e condições operacionais, tais como: estufa com circulação de ar a $40^{\circ} \mathrm{C}$ por $48 \mathrm{~h}$ (SILVEIRA et al. 2010); $50^{\circ} \mathrm{C}$ por 6 $\mathrm{h}$ (ANTELO, COSTA \& KALIL, 2008); freeze-drying e secagem solar (CHAIKLAHAN et al. 2011). No entanto, estudos relatam que a ficocianina presente na Arthrospira Spirulina é extremamente sensível ao tratamento térmico, resultando na precipitação e perda da sua coloração natural, o que limita a sua utilização em alimentos e indústria farmacêutica (CHAIKLAHAN, CHIRASUWAN \& BUNNAG, 2012). Diante disso, torna-se necessário o estudo de técnicas de secagem e condições operacionais para preservar e obter menores perdas deste pigmento.

A secagem em leito de jorro é uma técnica que tem sido empregada na secagem de pastas e suspensões, e possibilidade de obter um produto de qualidade similar ao spray dryer (BEZERRA et al. 2013). Como a Arthrospira Spirulina é extraída no cultivo como uma suspensão de aproximadamente $5 \%$ sólidos $(\mathrm{m} / \mathrm{m})$, a secagem em leito de jorro torna-se uma alternativa viável. A secagem em bandeja é uma técnica tradicional que tem sido amplamente utilizada para obtenção de biomassa seca (DESMORIEUX et al., 2010; DISSA et al., 2010; OLIVEIRA et al., 2010). Porém, devido ao longo tempo de secagem do material em contato com elevadas temperaturas, pode ocasionar perdas nos compostos termossensíveis como a ficocianina. Por esse motivo, uma comparação de técnicas que envolvem diferentes condições operacionais e tempos de residência devem ser investigadas, com o propósito de avaliar o comportamento dos compostos de interesse.

Além da obtenção da biomassa seca, um processo conhecido como ruptura celular das microalgas tem-se destacado para obtenção de lipídios para produção de biodiesel (LEE et al.,2010), extração de proteínas (SAFI et al., 2014) e na extração de pigmentos (MORAES, BURKERT \& KALIL， 2010; DEY \& RATHOD, 2013). O rompimento celular envolve a liberação de compostos intracelulares através da aplicação de diversos métodos, como: ultrassom, tratamentos abrasivos como moagem, tratamento químico, congelamento, variação na pressão osmótica, micro-ondas, autoclavagem, dentre outros (MORAES, BURKERT \& KALIL， 2010; PRABAKARAN \& RAVINDRAN, 2011). Diante dos fatos relatados, este trabalho tem como objetivo analisar diferentes técnicas de secagem (leito de jorro e bandeja) e métodos de ruptura celular a fim de verificar a influência na concentração de ficocianina da Arthrospira Spirulina.

\section{MATERIAL E MÉTODOS}

\subsection{Matéria-prima}

Arthrospira Spirulina cepa LEB-18 (MORAIS et al., 2008) foi cedida pelo Laboratório de Engenharia Bioquímica-LEB, da Universidade Federal do Rio GrandeFURG. A microalga foi cultivada na Unidade Piloto em Santa Vitória do Palmar/RS, realizada em fotobiorreatores abertos em condições não controladas, segundo Morais et al. (2009), contendo 20\% (v/v) de meio de cultivo Zarrouk e preparado com a água da Lagoa da Mangueira para manutenção do inóculo (COSTA et al. 2004). Ao final do cultivo, a microalga foi coletada, filtrada (200 mesh) e prensada com uma concentração de sólidos de $20 \%$ (m/m). 


\subsection{Secagem da Spirulina}

\subsubsection{Leito de Jorro}

A secagem em leito de jorro da Arthrospira Spirulina foi realizada na geometria cônica, constituída por duas bases cônicas de vidro de $15 \mathrm{~cm}$ de altura, diâmetros de $17,5 \mathrm{~cm}$, ângulo incluso de $60^{\circ} \mathrm{e}$ diâmetro de orifício de entrada do ar de 2,9 $\mathrm{cm}$. Uma carga de inertes de $0,5 \mathrm{~kg}$ de partículas de polietileno (inertes) foi utilizada como suporte para secagem da biomassa. As partículas de polietileno apresentavam um diâmetro médio de $3,2 \mathrm{~mm}$, esfericidade de 0,7 e massa específica de $0,96 \mathrm{~g} . \mathrm{cm}^{-3}$.

$\mathrm{O}$ ar de secagem era transportado por meio de um soprador radial, e aquecido por três resistores de $800 \mathrm{~W}$ cada um. A vazão de ar foi medida por uma placa de orifício, acoplada a um manômetro de tubo em U, sendo utilizada uma taxa de circulação de sólidos de $100 \%$ acima da velocidade de jorro mínimo, indicado para secagem de pastas e suspensões (EPSTEIN \& GRACE, 2011). As temperaturas do ar de secagem foi medida por termopares do tipo cobre-constantan,.

A biomassa foi diluída até atingir uma concentração de $5 \%(\mathrm{~m} / \mathrm{m})$ de sólidos, sendo alimentada na célula de secagem por uma seringa de capacidade de $50 \mathrm{~mL}$, a uma altura de $23 \mathrm{~cm}$ da base do leito e, atomizada utilizando ar comprimido a uma pressão de $200 \mathrm{kPa}$ abs. A suspensão de Arthrospira Spirulina após seca formava-se um pó fino, sendo recuperado pelo ciclone do tipo Lapple e coletado em um recipiente de vidro.

Através de testes preliminares foram determinados as condições operacionais para a secagem da Arthrospira Spirulina em leito de jorro, sendo assim fixado uma taxa de alimentação de $0,4 \mathrm{~kg}$ suspensão. $\mathrm{kg}$ inerte. $\mathrm{h}^{-1} \mathrm{e}$ temperatura do ar de entrada de $95 \pm 1^{\circ} \mathrm{C}$. Os experimentos foram realizados em réplica, com duração de $6 \mathrm{~h}$.

\subsubsection{Bandeja}

A secagem em bandeja com escoamento paralelo do ar foi realizada segundo Oliveira et al., (2010). A biomassa de Arthrospira Spirulina foi colocada em bandejas perfuradas, sendo utilizada uma seringa plástica para formar os pellets cilíndricos com diâmetro de $4 \mathrm{~mm}$. A biomassa foi seca a $55^{\circ} \mathrm{C}$ e velocidade do ar de $2,5 \mathrm{~m} . \mathrm{s}^{-1}$. Os experimentos de secagem tiveram a duração de $210 \mathrm{~min}$, e foram realizados em réplica. A biomassa seca foi recolhida das bandejas e padronizado o seu tamanho de partícula utilizando um moinho de facas (35 mesh).

As amostras secas em leito de jorro e bandeja foram submetidas ao processo de rompimento celular a fim de avaliar a influência no conteúdo de ficocianina.

\subsection{Rompimento celular}

\subsubsection{Moagem}

Amostra de $150 \mathrm{~g}$ de Arthrospira Spirulina seca foi colocada no moinho de bolas com volume de $0,0043 \mathrm{~m}^{3}$, sendo o volume total ocupado pela amostra e as bolas de porcelanas de $21 \%$. A ruptura ocorreu por $2 \mathrm{~h}$.

\subsubsection{Micro-ondas}

A ruptura da biomassa por micro-ondas (Sanyo, EM804TGR, Brazil) foi realizada segundo o método de Lee et al., (2010), com modificações. Através de testes preliminares foi utilizado $0,5 \mathrm{~g}$ de amostra de biomassa seca distribuída numa placa de Petri por 2 min. A potência do micro-ondas utilizada foi de $1400 \mathrm{~W}$ numa frequência de $2450 \mathrm{MHz}$.

\subsubsection{Autoclavagem}

A ruptura celular por autoclavagem foi realizada utilizando uma amostra de $5 \mathrm{~g}$ de biomassa seca numa autoclave (Stermax, vertical Model 16052, Brazil) durante $30 \mathrm{~min}$ a uma pressão absoluta de 0,2 MPa. Após o processo de ruptura, a amostra foi submetida 
à secagem numa estufa a vácuo na temperatura de $40^{\circ} \mathrm{C}$ e pressão de vácuo de $100 \mathrm{mmHg}$ para remoção de água absorvida no processo.

\subsection{Metodologia analítica}

\subsubsection{Determinação do conteúdo de ficocianina}

A determinação do conteúdo de ficocianina das amostras foi analisada utilizando método de Silveira et al., (2007), modificado por Moraes, Burkert \& Kalil (2010). As amostras foram dissolvidas em água destilada na proporção de $0,16 \mathrm{~g}_{\text {biomassa }}$ seca. $\mathrm{mL}_{\text {solvente }^{-1} \text {, sendo submetidas à agitação }}$ sob $100 \mathrm{rpm}$ em shaker durante $4 \mathrm{~h}$ e centrifugadas a $3500 \mathrm{rpm}$ durante $20 \mathrm{~min}$. Após a separação, as amostras foram filtradas em papel filtro, e uma alíquota foi diluída em $25 \mathrm{~mL}$ para leitura no espectrofotômetro nos comprimentos de onda 620 e $652 \mathrm{~nm}$. A concentração da fiocianina foi calculada segundo Bennett e Bogorad (1973) de acordo com a Equação 1.

$$
F c=\frac{a b s_{620}-0,474\left(a b s_{652}\right)}{5,34}
$$

\subsubsection{Análise de FTIR}

Os extratos aquosos de ficocianina foram analisados no espectro de infravermelho, a fim de identificar os principais picos que representam os grupos funcionais da ficocianina presentes na Arthrospira Spirulina, utilizando a água destilada como branco.

A análise se baseia na espectroscopia da transformada de Fourier (FTIR) de acordo com a refletância atenuada total horizontal (HATR), através de um prato de cristal com um ângulo de abertura de $45^{\circ}$. As análises foram realizadas em temperatura ambiente de $20^{\circ} \mathrm{C}$ utilizando uma varredura através da frequência de $4000-800 \mathrm{~cm}^{-1}$ na resolução de
$4 \mathrm{~cm}^{-1}$, com quarenta e cinco varridas por alíquota.

\subsubsection{Microscopia eletrônica de varredura}

As amostras de Arthrospira Spirulina secas em leito de jorro e bandeja com e sem ruptura foram analisados a sua estrutura morfológica pela análise de microscopia eletrônica de varredura (MEV), sendo recobertas por uma camada de ouro nos stubs antes do procedimento.

\subsection{Análise estatística}

Os resultados foram analisados estatisticamente pelo teste de Tukey ao nível de $95 \%$ de significância $(\mathrm{p}<0,05)$.

\section{RESULTADOS E DISCUSSÃO}

\subsection{Conteúdo de ficocianina}

Os conteúdos de ficocianina avaliados na amostra in natura, em diferentes técnicas de secagem (leito de jorro e bandeja), e métodos de ruptura (moagem, micro-ondas e autoclavagem), estão mostrados na Figura 1.

Figura 1 - Conteúdos de ficocianina (FC) das diferentes técnicas de secagem e métodos de ruptura.

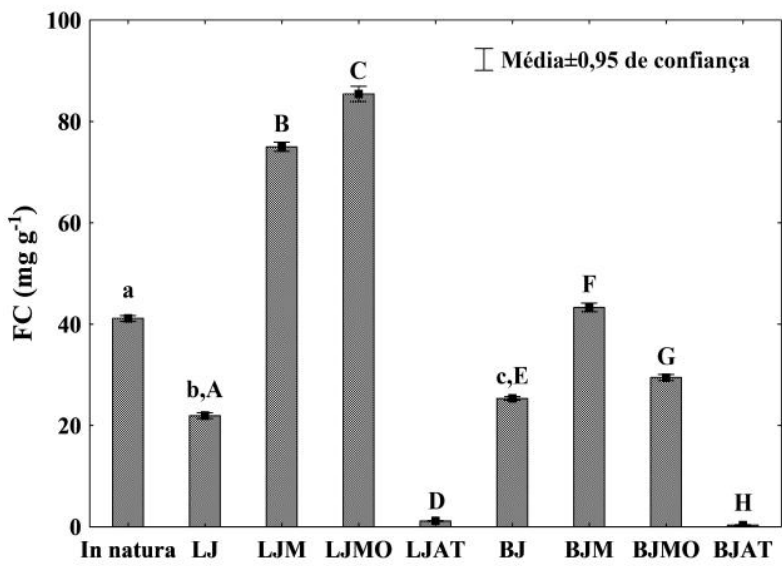

Legenda: LJ=leito de jorro; LJM=leito de jorro moagem; LJMO=leito de jorro micro-ondas; LJAT=leito de jorro autoclave; $\mathrm{BJ}=$ bandeja; $\mathrm{BJM}=$ bandeja moagem; $\mathrm{BJMO}=$ bandeja micro-ondas; $\mathrm{BJAT}=$ bandeja autoclave. Letras diferentes apresentam diferença significativa $(\mathrm{p}<0,05)$. 
Observando os resultados dos conteúdos da ficocianina na Figura 1, observa-se que a Arthrospira Spirulina in natura em relação às amostras submetidas à secagem apresentaram diferença significativa ao nível $95 \%$ de significância $(\mathrm{p}<0,05)$. No entanto, os experimentos de secagem sem método de ruptura em leito de jorro proporcionou perdas de $46,7 \%$, e em bandeja apresentou perdas de $38,4 \%$, valores estes superiores aos encontrados na literatura de $37 \%$ por OLIVEIRA et al., (2010).

Comparando-se as amostras secas em leito de jorro e bandeja em relação aos métodos de ruptura celular, observa-se na Figura 1 que para o leito de jorro, a ruptura por micro-ondas foi a que obteve melhores resultados, seguido da moagem. Ocorrendo um aumento dos valores acima de 100\%, mostrando ser quatro vezes maior em relação à amostra sem ruptura. Enquanto que na secagem em bandeja, a moagem foi mais efetiva para extrair a ficocianina, obtendo um aumento de $71 \%$ em relação à amostra seca em bandeja sem ruptura.

A ruptura celular por micro-ondas ocorre devido à intensa vibração de moléculas de água no interior da biomassa pelo aquecimento, fazendo com que a ficocianina seja liberada dos vacúolos celulares. Segundo Kim et al. (2013), as micro-ondas podem rapidamente aquecer a biomassa para provocar danos nas camadas celulares e quebrar diretamente as pontes fracas de hidrogênio nessas camadas. Portanto, a radiação provocada pelas micro-ondas é vantajosa, devido à sua rápida penetração em biomassa, o que resulta numa rápida ruptura celular.

Na moagem, o processo contribui para desintegração e redução do tamanho da partícula a tamanhos menores que a original, rompendo as paredes celulares e liberando seus compostos, devido às tensões de compressão pelas bolas de porcelana utilizadas no moinho. No entanto, o método de autoclave não foi eficiente para as amostras de Arthrospira Spirulina, pois apresentou o maior índice de perda, de quase $100 \%$ da ficocianina em relação às amostras sem ruptura. Isso se deve à elevada temperatura de vapor de água aplicada no processo e durante ao longo tempo de exposição, degradando a ficocianina pela reação de escurecimento não-enzimático com formação produtos da reação de Maillard, como as melanoidinas.

A Arthrospira Spirulina por ser uma "micro" alga, possui uma parede celular rígida de várias camadas dificultando a extração de compostos intracelulares. No entanto, ao submeter processos de ruptura, faz com que a ficocianina que está presente nos tilacóides dos cloroplastos, seja liberada em maior concentração. Por esse motivo, após o rompimento celular das amostras secas foram alcançados maiores concentrações de ficocianina em relação às amostras secas sem ruptura, conforme apresentado na Figura 1. Cabe salientar que o conteúdo de ficocianina na biomassa in natura foi menor que nas amostras secas com ruptura, pois não foi rompida a célula. Logo, a comparação da biomassa in natura foi em relação ao processo de secagem.

\subsection{Análise dos espectros de infravermelho de FTIR}

Os extratos aquosos de ficocianina das amostras secas sem e com ruptura celular também foram avaliados pela análise de infravermelho pela FTIR de acordo com as Figuras 2 e 3. 
Figura 2 - FTIR dos extratos aquosos de ficocianina das amostras de Arthrospira Spirulina secas em (a) leito de jorro sem ruptura; (b) leito de jorro moagem; (c) leito de jorro micro-ondas; (d) leito de jorro autoclave.

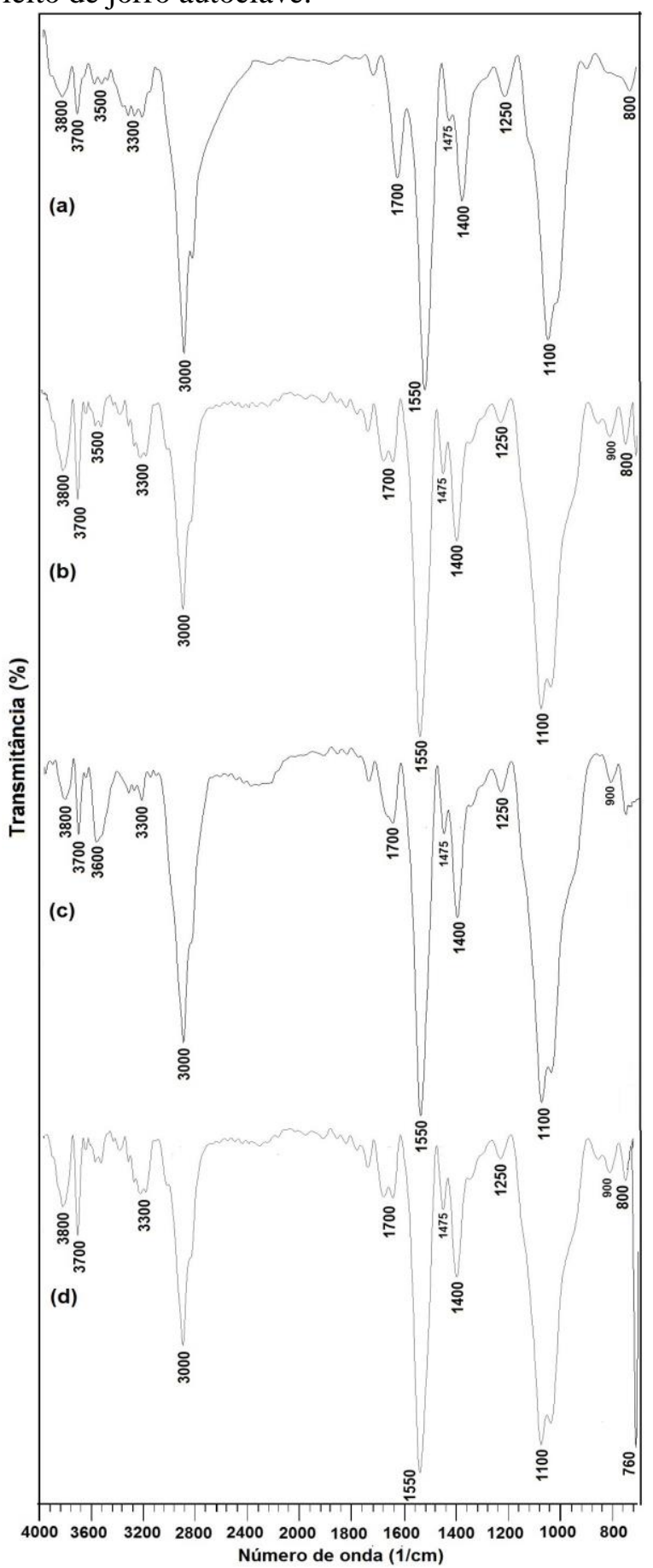

Fonte: autores (2015).
Figura 3 - FTIR dos extratos aquosos de ficocianina das amostras de Arthrospira Spirulina secas em (a) bandeja sem ruptura; (b) bandeja moagem; (c) bandeja micro-ondas; (d) bandeja autoclave.

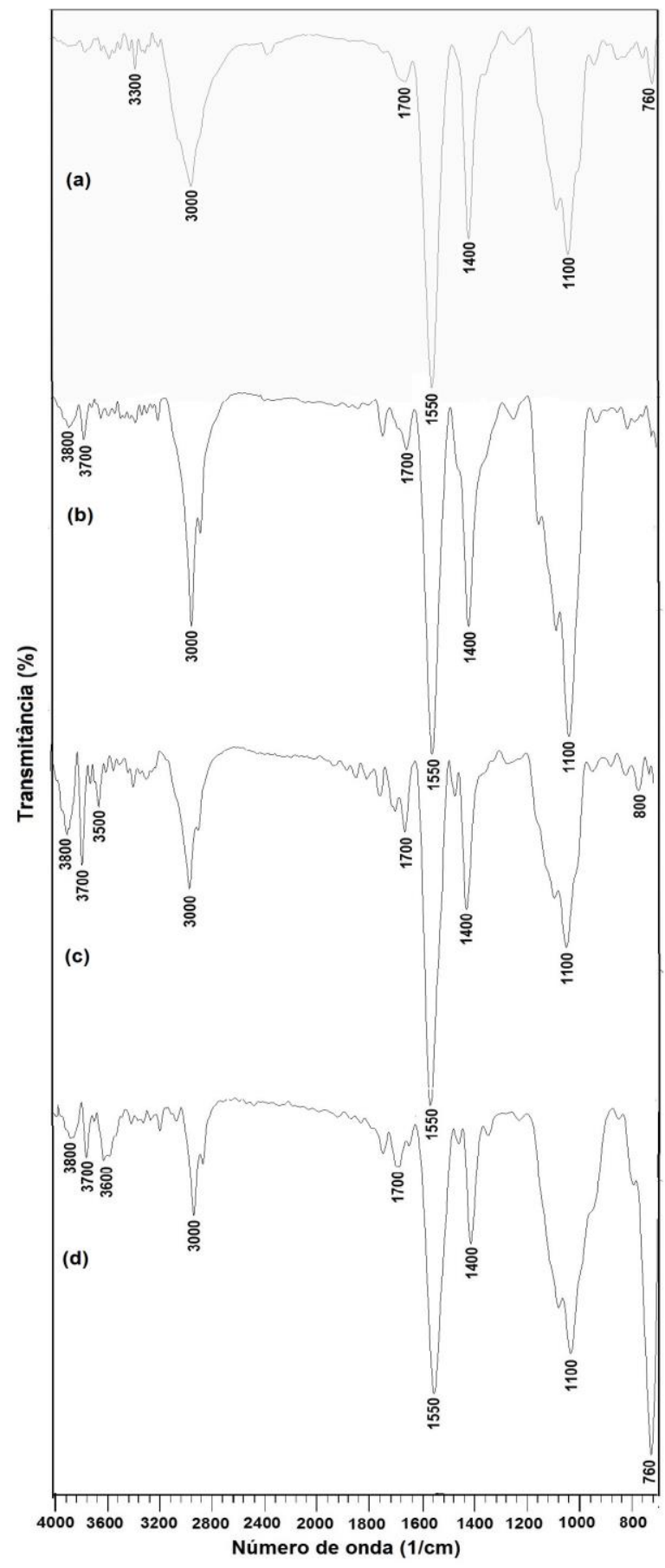

Fonte: autores (2015). 
Analisando os espectros das amostras nas Figuras 2 e 3, foram identificadas as seguintes bandas características da estrutura da ficocianina: 3800 a $3500 \mathrm{~cm}^{-1}$ correspondem ao estiramento do plano dos grupos -OH livres; $3300 \mathrm{~cm}^{-1}$ que corresponde a deformação axial da ligação $\mathrm{N}-\mathrm{H}$ das aminas primárias; região de $3000 \mathrm{~cm}^{-1}$ que corresponde a deformação axial simétrica e assimétrica de $\mathrm{C}-\mathrm{H} ; 1700 \mathrm{~cm}^{-1}$ corresponde ao estiramento vibracional forte de $\mathrm{C}=\mathrm{O}$; na região de $1550 \mathrm{~cm}^{-1}$ corresponde à deformação angular do grupamento $\mathrm{N}-\mathrm{H}$; $1400 \mathrm{~cm}^{-1}$ corresponde à deformação angular de $\mathrm{C}-\mathrm{H} ; 1250$ corresponde ao estiramento de $\mathrm{C}-\mathrm{N}$; na região de $1100 \mathrm{~cm}^{-1}$ corresponde à deformação axial de $\mathrm{C}-\mathrm{O}-\mathrm{H}$; e bandas nas regiões de 900 a $760 \mathrm{~cm}^{-1}$ compreendem as regiões de deformação de $\mathrm{C}-\mathrm{H}$ fora do plano (SILVERSTEIN, WEBSTER \& KIEMLE, 2005).

$\mathrm{Na}$ amostra seca em bandeja sem ruptura foram observadas algumas bandas com menor intensidade do que na amostra seca em leito de jorro sem ruptura na região de $3000 \mathrm{~cm}^{-1}, 1700 \mathrm{~cm}^{-1}$ e $1100 \mathrm{~cm}^{-1}$. Além disso, na região de $1100 \mathrm{~cm}^{-1}$ apresentou um agrupamento de compostos com o C-O-H. A sobreposição de bandas próximas o que pode indicar uma preservação destes grupamentos, o pode indicar as menores perdas de ficocianina na amostra seca em bandeja sem ruptura em relação à secagem em leito de jorro.

Em relação às amostras secas sem ruptura e com ruptura, foi observado algumas modificações em diversas bandas. $\mathrm{Na}$ amostra seca em leito de jorro e rompida por microondas, a qual apresentou maior conteúdo de ficocianina do que as demais amostras, apresentou picos na região de $3000 \mathrm{~cm}^{-1}(\mathrm{C}-\mathrm{H})$ e $1700 \mathrm{~cm}^{-1}(\mathrm{C}=\mathrm{O})$ com maior intensidade do que as amostras rompidas por moagem e autoclavagem. Enquanto que, nas amostras secas em bandeja, a amostra rompida pela moagem apresentou o grupamento $\mathrm{C}-\mathrm{H}$ mais intenso na região de $3000 \mathrm{~cm}^{-1}$. Também, foi observado uma sobreposição de derivados de $\mathrm{C}-\mathrm{O}-\mathrm{H}$ na região de $1100 \mathrm{~cm}^{-1}$ do que as demais amostras, com maior intensidade.

Além disso, observa-se claramente, que as amostras obtidas por ruptura celular, apresentou redução ou desdobramento do grupo carbonila $(\mathrm{C}=\mathrm{O})$ na região de $1700 \mathrm{~cm}^{-}$ 1 , devido à formação de derivados desse grupamento, mostrando que a ruptura celular provoca uma perturbação nos grupamentos e consequentemente no conteúdo de ficocianina.

Outro aspecto relevante que foi observado nos espectros está relacionado ao processo de autoclave. Tanto na amostra seca em leito de jorro quanto na bandeja obtida por este método de rompimento celular, apresentaram um pico pronunciado na região de $760 \mathrm{~cm}^{-1}$ com maior intensidade na bandeja do que no leito de jorro, provavelmente devido à formação de subprodutos da reação de degradação da ficocianina.

\subsection{Microscopia eletrônica de varredura dos produtos desidratados}

As Figuras 4 e 5 apresentam as estruturas morfológicas realizadas nas amostras secas nas diferentes técnicas e métodos de ruptura. 
Figura 4 - Microscopia eletrônica de varredura (MEV) das amostras secas em (a) leito de jorro sem ruptura; (b) leito de jorro moagem; (c) leito de jorro micro-ondas; (d) leito de jorro autoclave.

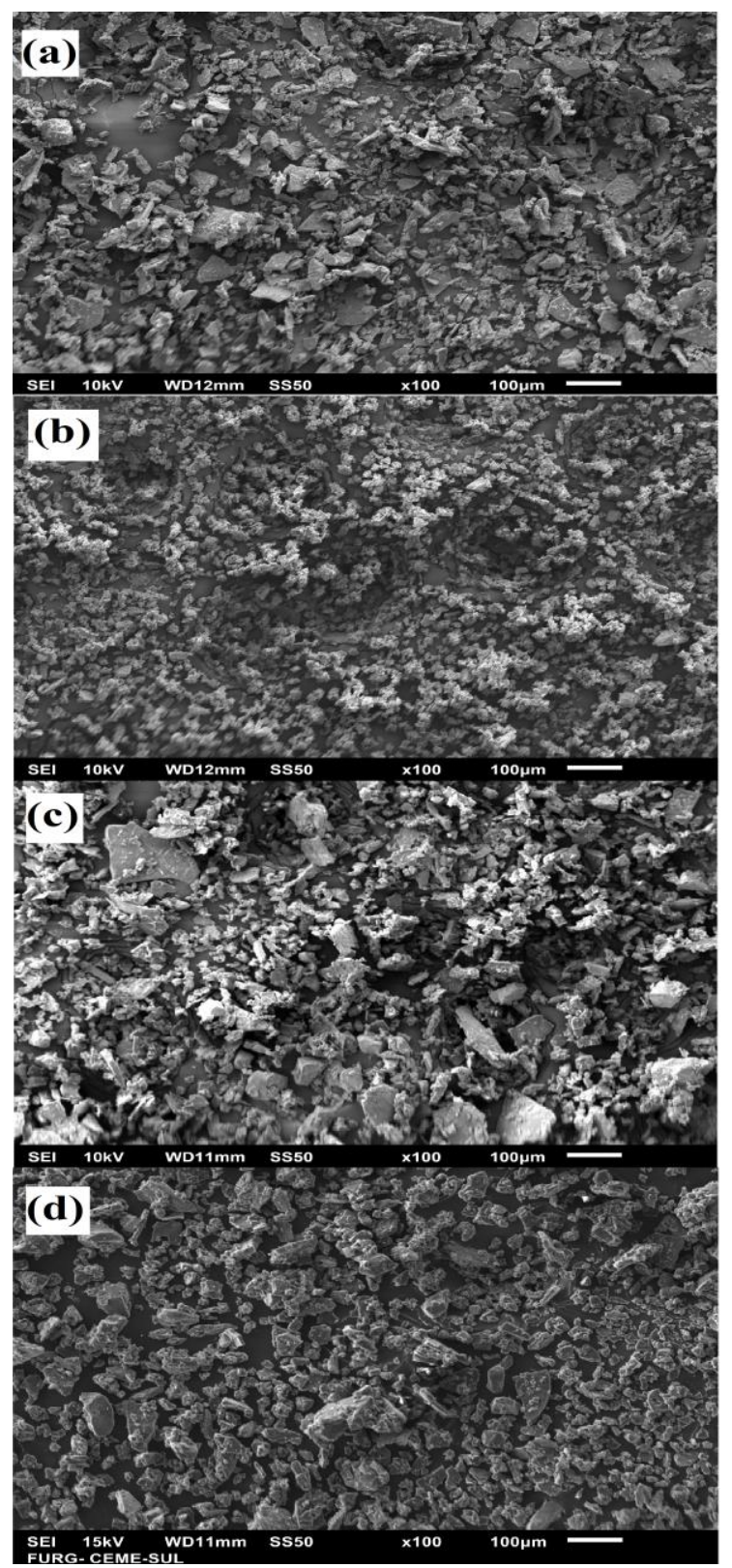

Fonte: autores (2015).
Figura 5 - Microscopia eletrônica de varredura (MEV) das amostras secas e em (a) bandeja sem ruptura; (b) bandeja moagem; (c) bandeja microondas; (d) bandeja autoclave.

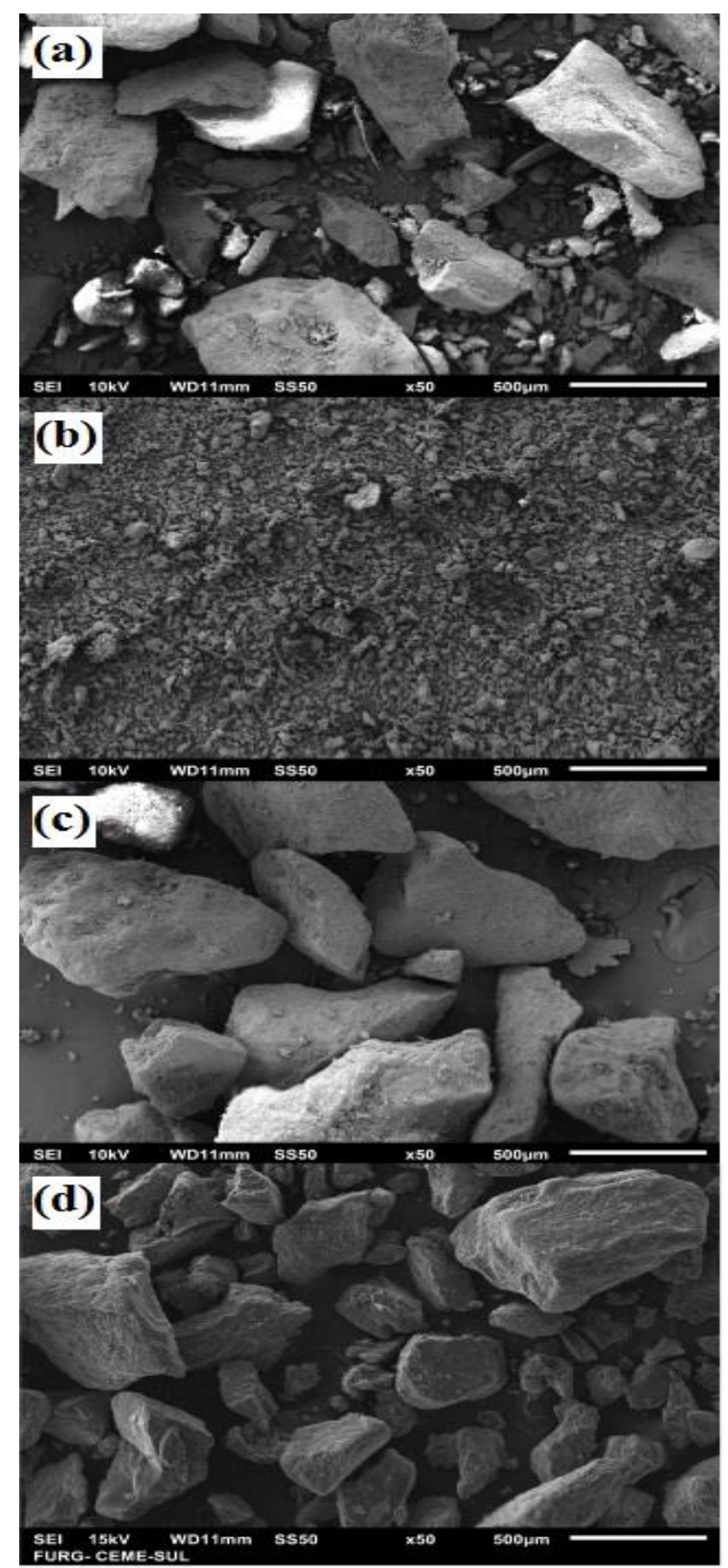

Fonte: autor (2015).

As partículas de Arthrospira Spirulina secas em leito de jorro $(<100 \mu \mathrm{m})$ e bandeja $(<500 \mu \mathrm{m})$ apresentaram estrutura irregular, compacta e rugosa. As amostras rompidas por moagem apresentaram redução na 
granulometria com partículas mais aglomeradas; as amostras rompidas por micro-ondas não apresentaram diferença na estrutura morfológica e; as amostras rompidas por autoclave apresentaram uma redução da rugosidade das partículas, devido ao superaquecimento.

\section{CONCLUSÃO}

Diante do estudo apresentado neste trabalho, pode-se verificar que as técnicas de secagem em leito de jorro e bandeja, sem método de ruptura da biomassa, apresentaram perdas de ficocianina de 47 e $38 \%$, respectivamente, em relação à amostra in natura (41 mg. $\left.{ }^{-1}\right)$. No entanto, ao utilizar o método de ruptura celular por micro-ondas em leito de jorro obteve maior extração de ficocianina do que os demais métodos e do que amostra in natura, apresentando um valor de $85 \mathrm{mg} \cdot \mathrm{g}^{-1}$. Para a amostra seca em bandeja, a amostra rompida pela moagem apresentou os melhores resultados na extração da ficocianina (43 $\mathrm{mg} \cdot \mathrm{g}^{-1}$ ). O método de ruptura celular realizado pela autoclave nas amostras secas em leito de jorro e bandeja não foi satisfatório devido à degradação da ficocianina. Sendo observado nos espectros de infravermelho mudanças nas bandas dos grupamentos característicos deste pigmento.

\section{REFERÊNCIAS}

ANTELO, F. S.; COSTA, J. A. V.; KALIL, S. J. Thermal degradation of the phycocyanin from Spirulina platensis. Biochemical Engineering Journal, 41, 43-47, 2008.

BEZERRA, C. V.; AMANTE, E. R.; DE OLIVEIRA, D. C.; RODRIGUES, A. M. C.; DA SILVA, L. H. M. Green banana (Musa cavendishii) flour obtained in spouted bedEffect of drying on physico-chemical, functional and morphological characteristics of the starch. Industrial Crops and Products, 41, p.241-249, 2013.
CHAIKLAHAN, R.; CHIRASUWAN, N.; BUNNAG, B. Stability of phycocyanin extracted from Spirulina sp.: influence of temperature, $\mathrm{pH}$ and reservatives. Process Biochemistry, 47, p.659-664, 2012.

COSTA, J. A. V.; COLLA, L. M.; FILHO, P. F. D. Improving Spirulina platensis biomass yield using a fed-batch process. Bioresource Technology, 92, p.237-241, 2004.

DESMORIEUX, H.; MADIOULI, J.; HERRAUD, C.; MOUAZIZ, H. Effect of size and form of Arthrospira Spirulina biomass on the shrinkage and porosity during drying. Journal of Food Engineering, 100, p. 585$595,2010$.

DEY, S.; RATHOD, V. K. Ultrassound assisted extraction of $\beta$-carotene from Spirulina platensis. Ultrasonics Sonochemistry, 20, p. 271-276, 2013.

DISSA, A. O.; DESMORIEUX, H.; SAVADOGO, P. W.; SEGDA, B. G.; KOULIDIATI, J. Shrinkage, porosity and density behaviour during convective drying of Spirulina. Journal of Food Engineering, 97, p. 410-418, 2010.

FERNÁNDEZ-ROJAS， B.; HERNÁNDEZJUÁREZ， J.; PEDRAZA-CHAVERRI， J. Nutraceutical properties of phycocyanin. Journal of Functional Foods, 11, p.375-392, 2014.

KIM, J.; YOO, G.; LEE, H.; LIM, J.; KIM, K.; KIM, C. W.; PARK, M. S.; YANG, J-W. Methods of downstream processing for the production of biodiesel from microalgae. Biotechnology Advances, 31, 862-876, 2013.

LEE, J.- Y.; YOO, C.; JUN, S.-Y.; AHN, C.$\mathrm{Y}$; OH, H.-M. Comparison of several methods for effective lipid extraction from microalgae. 
Bioresource Technology, 101, p. 75-77, 2010.

MARTELLI, G.; FOLLI, C.; VISAI, L.; DAGLIA, M.; FERRARI, D. Thermal stability improvement of blue colorant CPhycocyanin from Spirulina platensis for food industry applications. Process Biochemistry, 49, p.154-159, 2014.

MORAES, C. C.; BURKERT, J. F. M.; KALIL, S. J. C-phycocyanin extraction process for large-scale use. Journal of Food Biochemistry, v. 34, n. 1, p. 133-148, 2010.

MORAIS, M. G.; REICHERT, C. C.; DALCANTON, F.; DURANTE, A. J.; MARINS, L. F.; COSTA, J. A. V. Isolation and characterization of a new Arthrospira strain. Z. Naturforsch. 63, 144-150, 2008.

MORAIS, M. G.; RADMANN, E. M.; ANDRADE， M. R.; TEIXEIRA， G. G.; BRUSCH, L. R. F.; COSTA, J. A. V. Pilot scale semicontinuous production of Spirulina biomass in southern Brazil. Aquaculture, 294, p.60-64, 2009.

NUHU, A. A. Spirulina (Arthrospira): an important source of nutritional and medicinal compounds. Journal of Marine Biology, p.19, 2013.

OLIVEIRA, E. G.; DUARTE, J. H.; MORAES, K.; CREXI, V. T.; PINTO, L. A. A. Optimisation of Spirulina platensis convective drying: evaluation of phycocyanin loss and lipid oxidation. International Journal of Food Science \& Technology, 45, p. 1572- 1578, 2010.

PAKABARAN, P.; RAVINDRAN, A. D. A comparative study on effective cell disruption methods for lipid extraction from microalgae. Letters in Applied Microbiology, 53, p.150154,2011
SAFI, C.; URSU, A. V.; LAROCHE, C.; ZEBIB, B.; MERAH, O.; PONTALIER, P-Y; VACA-GARCIA, C. Aqueous extraction of proteins from microalgae: effect of different cell disruption methods. Algal Research, 3, p.61-65, 2014.

SILVEIRA，S. T.; BURKERT, J. F. M.; COSTA, J. A. V.; BURKERT, C. A. V.; KALIL, S. J. Optimization of phycocyanin extraction from Spirulina platensis using factorial design. Bioresource Technology, 98, p. 1629-1634, 2007.

SILVERSTEIN, R.M., WEBSTER, F.X., KIEMLE, D.J. Spectrometric Identification of Organic Compounds (7 th ed). Wiley, New York, NY, 2005.

YAN, M.; LIU, B.; JIAO, X.; QIN, S. Preparation of phycocyanin microcapsules and its properties. Food and Bioproducts Processing, 92, p.89-97, 2014.

\section{AGRADECIMENTOS}

Os autores deste trabalho agradecem à CAPES pelo auxílio financeiro, ao Laboratório de Engenharia Bioquímica LEB/FURG pela matéria-prima e pelo CEME-SUL pela análise de microscopia eletrônica de varredura (MEV). 